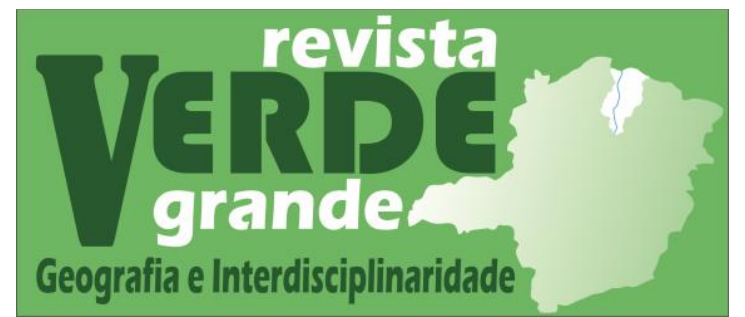

Volume 01, nㅇ. 01, 2019

https://www.periodicos.unimontes.br/index.php/verdegrande

\title{
RESENHA \\ MINERAÇÃO, VIOLÊNCIAS E RESISTÊNCIAS: Um campo aberto à produção de conhecimento no Brasil (2018)
}

Bruna França Oliveira ${ }^{1}$ https://orcid.org/0000-0001-8987-510X

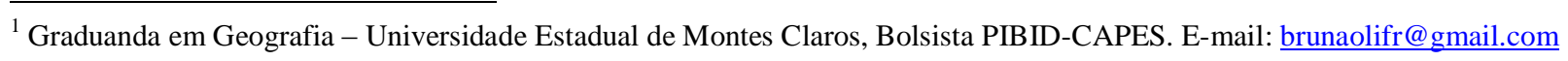

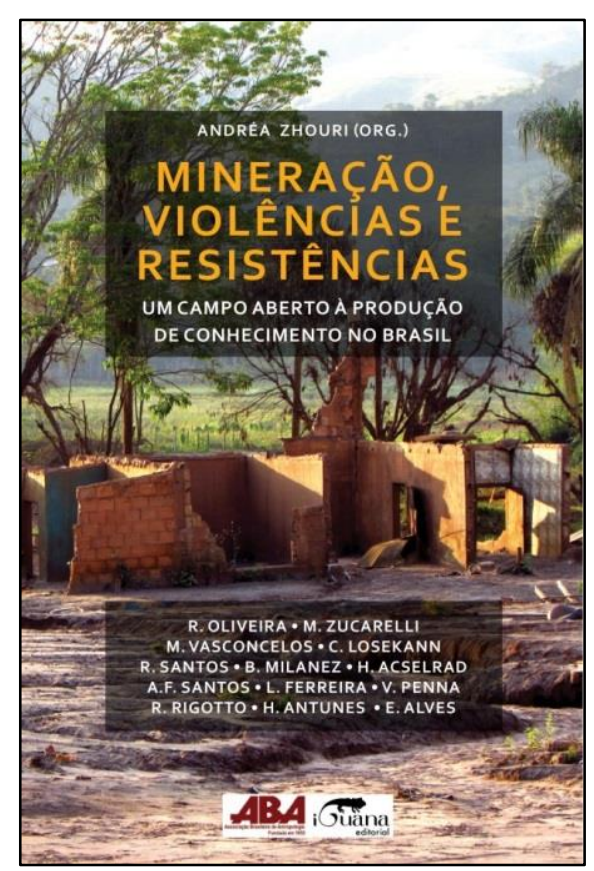

A coletânea "Mineração, violências e resistências: um campo aberto à produção de conhecimento no Brasil" é uma obra organizada pela pesquisadora Andréa Zhouri com o propósito de discorrer sobre os conflitos gerados pelos empreendimentos minerários no Brasil e analisar como esses conflitos se apresentam como um importante campo para estudos.

Na apresentação da coletânea, Zhouri (2018) aponta a principal problemática do livro, a formação de novas fronteiras minerárias no país que adentra a territórios tradicionalmente ocupados, devido ao boom das commodities que atinge a América Latina no início do século XXI. Essas áreas irão se caracterizar por serem focos de diversos conflitos tanto de ordem social como ambiental e, por estarem sujeitas à dinâmica econômica internacional, são passíveis de sofrerem efeitos de diversas ordens.

A coletânea é dividida em duas partes, a primeira parte intitula-se: "O desastre da Samarco - afetações, resistências, políticas" e abrange quatro capítulos, que debatem o desastre do colapso da barragem de rejeitos da Samarco no município de Mariana, Minas Gerais. A segunda parte "Violências, resistências e produção de 
conhecimento", compreende três capítulos que versam sobre distintos projetos minerários do país. Ambos são resultados de pesquisas de campo e apresentam análises a respeito dos conflitos e desigualdade desencadeados pelos processos minerários, trazendo as concepções dos atingidos pelo empreendimento, os assédios e as ameaças que enfrentam, bem como suas mobilizações.

O primeiro capítulo intitulado "O Desastre no Rio Doce: entre as políticas de reparação e a gestão das afetações", são dos autores Andréa Zhouri, Raquel Oliveira, Marcos Zucarelli e Max Vasconcelos, integrantes do Grupo de Estudos em Temáticas Ambientais da Universidade Federal de Minas Gerais (GESTA-UFMG). Nesse capítulo os autores discutem as políticas de afetações e suas consequências, bem como abordam as medidas adotas pela Samarco para reconhecer os afetos pelo rompimento da barragem de Fundão no município de Mariana.

O cadastramento realizado pela empresa com a finalidade de levantar os impactados pelo desastre mostra-se, a partir de narrativas dos atingidos, como um processo que gera violência, sofrimento e constrangimento social. Puramente quantitativo, o cadastro se concentra em questões de perdas materiais e diretas, não se preocupando com danos desencadeados pelo desastre, bem como pelo rompimento do modo de vida e organização social e, dessa forma, com o universo cultural simbólico das comunidades locais.

O capítulo 2 "Não Foi Acidente! O lugar das emoções na mobilização dos afetados pela ruptura da barragem de rejeitos da mineradora Samarco no Brasil" foi escrito por Cristiana Losekann, professora do Departamento de Ciências Sociais e do Programa de Pós-Graduação em Ciências Sociais da Universidade Federal do Espírito Santo (UFES). Losekann aborda os atingidos pelo desastre no estado do Espírito Santo, foram apenas 11 dias para que a lama dos rejeitos chegasse ao estado trazendo diversas mudanças para as populações locais que dependiam da água do Rio Doce.

Movimentos que tem como pauta a mineração são, de maneira geral, recentes no Brasil, no estado do Espírito Santo eles surgem a partir do desastre da barragem de Fundão. Assim, com base nos terrenos das emoções e na dimensão do lugar dada pelos atingidos, a autora trabalha o aparecimento de mobilizações e de movimentos sociais no estado e a busca por justiça.

O capítulo 3 “A Construção do Desastre e a 'Privatização' da Regulação Mineral: reflexões a partir do caso do Vale do Rio Doce” é de autoria de Rodrigo Salles Pereira dos Santos e Bruno Milanez, participantes do Núcleo Política, Economia, Mineração, Ambiente e Sociedade (PoEMAS) pela Universidade Federal do Rio de Janeiro (UFRJ) e pela Universidade Federal de Juiz de Fora (UFJF), respectivamente. Os autores fazem uma análise do processo das políticas de regulamentação ambiental nacional, com ênfase nas atividades de extração mineral, apontando a atuação insuficiente do Estado e da iniciativa privada na auto-regulamentação que excluem a sociedade civil do processo.

Santos e Milanez fazem uma revisão referente ao setor ambiental brasileiro e como suas limitações institucionais e socioculturais viabilizaram o licenciamento da barragem de Fundão, bem como a atuação insuficiente dos órgãos ambientais no monitoramento de barragens que não garantem sua total segurança.

No capítulo 4 "Mariana, novembro de 2015: A genealogia política de um desastre”, de autoria do Henri Acselrad, pesquisador do ETTERN - Estado, Trabalho, Território e Natureza - laboratório da Universidade Federal do Rio de Janeiro (IPPUR-UFRJ,versa sobre a lógica econômica dos empreendimentos minerários e como essa proporciona os riscos ambientais devido à não preocupação com as consequências sociais e 
Resenha - Mineração, violências e resistências: Um campo aberto à produção de conhecimento no Brasil Bruna França Oliveira

ambientais dadas a partir da extração mineral e a participação das esferas políticas na legitimação dos empreendimentos.

Acselrad traz novos elementos a serem inseridos nos estudos dos debates de riscos ambientais, primeiro a irresponsabilidade organizada "de classe" que levanta o debate acerca da localização de instrumentos que se apresentam como fonte de risco, de acordo com as características sócio-raciais da população exposta. Também a rejeição dos alertas emitidos pela população em relação às ameaças relacionadas à extração mineral. E, por último, as restrições à liberdade acadêmica, em que o autor expõe os constantes constrangimentos que pesquisadores que estudam os impactos ambientais passam.

O capítulo 5, intitulado "Impactos Supostos, Violências Reais: A construção da legalidade na implantação do Projeto Minas-Rio”, é dos autores Ana Flávia Moreira Santos, Luciana da Silva Sales Ferreira e Vinicius Villela Penna integrantes do Grupo de Estudos em Temáticas Ambientais da Universidade Federal de Minas Gerais (GESTA-UFMG). É o primeiro artigo da segunda parte da coletânea e irá discutir os aspectos do Projeto Minas-Rio.

Neste capítulo, os autores utilizam narrativas de reuniões realizadas pela Rede de Acompanhamento Socioambiental (REASA), comandada pelo Ministério Público de Minas Gerais como meio de mediação de conflitos entre as partes, para expor a maneira como megaempreendimentos se constituem como transformadores do modo de vida das comunidades rurais locais devido aos impactos provocados na sua instalação. Ainda denuncia as ilegalidades no processo de concessão de licenças ambientais do projeto.

No capítulo 6 "Conhecimentos em Disputa no Conflito Ambiental em Torno da Mineração de Urânio e Fosfato no Ceará", escrito por Raquel Maria Rigotto, professora do Departamento de Saúde Comunitária e da Pós-graduação em Saúde Coletiva da Universidade Federal do Ceará, é discutido o processo de produção de conhecimento das comunidades locais relativo aos impactos ambientais da extração de urânio e fosfato na região dos munícipios de Santa Quitéria e Itatira, no Ceará.

Neste capítulo a autora apresenta a exclusão da sociedade civil no processo de produção dos Estudos de Impactos Ambientais e Relatório de Impacto Ambiental (EIA/RIMA) e sua busca por conhecimento e formação de militância local a partir da constituição da Articulação Antinuclear do Ceará (AACE). Relata, também, a importância que teve o intercâmbio com a população atingida pela mineração do urânio em Caitité - BA e com os pesquisadores da Universidade Federal do Ceará (UFC) na construção do ativismo da comunidade.

Por fim, temos o capítulo 7 "Mina-Ferrovia-Porto: no "Fim De Linha” uma cidade em questão", escrito por Horácio Antunes de Sant'Ana Júnior e Elio de Jesus Pantoja Alves, participantes do Grupo de Estudos Desenvolvimento, Modernidade e Meio Ambiente da Universidade Federal do Maranhão (Gedmma - UFMA). Os autores utilizam a ideia de 'efeito derrame' apresentada por Gudynas (2016) para discorrer como a mineração do sudeste do Pará provoca impactos em comunidades rurais em São Luís, Maranhão.

Apresentam como as infraestruturas demandadas pelo Programa Grande Carajás vêm provocando modificações na paisagem da Amazônia Oriental com grande consequência nos territórios e modo de vida de comunidades tradicionais. Em São Luís (Maranhão) iniciam-se projetos de desenvolvimentos que atingem a zona rural da capital, caracterizados com a introdução de atividades industriais, bem como outras instalações. Levanta-se o debate sobre a mudança na Lei de Zoneamento do município e as mobilizações sociais e resistências às construções das obras. 
Resenha - Mineração, violências e resistências: Um campo aberto à produção de conhecimento no Brasil Bruna França Oliveira

Dessa maneira, a coletânea se encerra constituindo-se como uma obra de grande contribuição para fomentar estudos referentes aos efeitos do setor minerário no país, uma vez que esse se apresenta como desencadeador de inúmeras contradições e desigualdades socioambientais.

\section{Referências}

GUDYNAS, E. Extractivismos en America der Sur: conceptos y sus efectos derrame”. In: A. Zhouri, P. Bolados, E. Castro (eds.). Mineração na América do Sul: neoextrativismo e lutas territoriais. São Paulo: Ed. Annablume, 2016.

ZHOURI, Andréa (Org.). Mineração, violências e resistências: Um campo aberto à produção de conhecimento no Brasil. Marabá - PA: Editorial iGuana; ABA, 2018 